\title{
Sustainability of meat sheep production in relation to health and reproduction traits
}

\begin{abstract}
Meat sheep production in most countries relies on grazing and profitability (gross margin per ewe and per year) is low. Profitability is in part based on the level of numeric productivity (number of lambs produced per ewe and per year). Numeric productivity depends on fecundity and survival rates of ewes and lambs. These survival rates are extremely variable from one farm to another. These variations are detrimental to sustainability of the farms. We will study the mortality rates of ewes and lambs and other health related traits, taken as indicator in meat sheep farms in different locations-plain or semi-mountain areas (34 farms) in relation to gross margin taken as an indicator of economical sustainability as well as other markers of sustainability. We constructed a method for evaluating sustainability based on the above mentioned parameters in the field of production, animal health, and economics. It was based on two step procedure: first, selection of farm parameters using clustering methods, second ranking farms on sustainability using principal component analysis with an orientation obtained by the incorporation in the analysis of two virtual farms (high and low sustainability) constructed on a choice of sustainability for each parameter. This choice of sustainability is flexible and dependant on the views of stakeholders and may modify the ranking of farms. The scale of sustainability we proposed was tested in relation to the management of the farm (organic or conventional) and location (plain or semi-mountain areas): the semi-mountain farms were more sustainable than plain farms and organic farms were often, but not always, more sustainable than conventional farms. The method can be easily applied to any animal production.
\end{abstract}

Volume 5 Issue I - 2017

\author{
Jacques Cabaret,' Marc Benoit, ${ }^{2}$ Gabriel \\ Laignel $^{2}$ \\ 'François Rabelais University, France \\ ${ }^{2}$ Saint Genès Champanelle, France
}

\begin{abstract}
Correspondence: Jacques Cabaret, INRA (French National Agronomy Research Institute), UMR I282, ISP and Tours University F. Rabelais, Nouzilly, F-37380, France, Tel +33 247427 768, Fax +33 247427 774, Email jacques.cabaret@inra.fr
\end{abstract}

Received: November 27, 2016 | Published: January 10, 2017

Keywords: numeric productivity, mortality, gross margin, meat sheep, sustainability ranking

\section{Introduction}

The term sustainability tends to refer to a balanced relationship among environmental, socio-cultural and economic aspects according to Bauer \& Mickan, ${ }^{1}$ which means that for a system to be sustainable, it should be technically feasible, environmentally sound and economically viable. It should fulfil some criteria: i) productivity, ii) stability, reliability and resilience, iii) adaptability, iv) equity, v) self-reliance (Framework for Evaluation of Natural Resource Management Systems: MESMIS, its Spanish acronym in Speelman $\mathrm{EN}){ }^{2}$ The problem is how to meet these results for each productive agro-ecosystem. In the past, conventional livestock farming has been impressively successful in its ability to improve the performance of farm animals and to decrease production costs. Animal farming systems are now expected to meet a number of objectives: to produce milk, meat, eggs and fibre, but also to minimize environmental damage and to improve animal welfare, biodiversity and environmental goods. Some authors consider that conversion to organic farming is the unique way for sustainable small ruminant farming ${ }^{3}$ whereas some others consider that conventional farmers may have proenvironmental preoccupations. ${ }^{4}$ There are various and complex pathways toward the "greening" of agrofood systems and that is why we will consider conventional and organic farmers. These pathways can be simplified into distinct scenarios as done for Swedish dairy production. ${ }^{5}$ Two scenarios for future dairy farms were constructed on a set of qualitative indicators: Specialised Dairy Farming (SDF) with high production intensity and Mixed Dairy Farming (MDF) with increased crop rotations and large share of pasture. The scenarios were evaluated concerning economics, environmental effects and animal welfare, including health. Cost of production per $\mathrm{kg}$ of milk was lower by $25 \%$ in SDF than in MDF scenario. SDF had more negative impact on the environment than MDF. Cows in SDF were found to have an increased risk of lameness, mastitis, ketosis and abomasal displacement compared to cows in the MDF scenario. No scenario was superior in all aspects and the goal for developing sustainable dairy farm production must be guided by analysis of values. ${ }^{5}$

Sustainability may be addressed by a wide range of markers of different importance according to the region and type of production (organic or not). The French IDEA method ("Indicateurs de Durabilité des Exploitations Agricoles" or Farm Sustainability Indicators) ${ }^{6}$ is one way of giving practical expression to the concept of sustainable farms. Based on 41 sustainability indicators covering the three dimensions of sustainability (economics, environment, and technical feasibility), this method is designed as a self-assessment tool not only for farmers but also for policy makers to support sustainable agriculture. It has been used for meat sheep in Algeria ${ }^{7}$ and indicates the strengths and weaknesses regarding agro-ecological and socioterritorial sustainability scores. It does not however give much weight to the economics and to the actual characteristics of the flocks. In a nationwide survey in Australia it was apparent that farmers have a range of views and exhibit a variety of behaviours in relation to environmental sustainability and they are resistant to nature preservation, particularly when it counters their productivity. ${ }^{8} \mathrm{~A}$ NewZealand survey on importance of research among sheep farmers ranked low the sustainability but had a high perceived importance of lamb 
survival and soils and fertilisers. ${ }^{9}$ Thus there is a need for objective measures. Our goal was to elaborate sustainability criteria based on the flock performances as a major determinant of sustainability, although other criteria were included. Thus we will investigate a wide range of selected meat sheep farm parameters including production, health and veterinary costs, and economical values that we know to characterize farms. ${ }^{10,11}$ We will investigate how the veterinary costs and mortality are part of sustainability since they vary largely from one farm to another. ${ }^{11}$ We will propose a method for ranking farms on a sustainability scale.

\section{Meat sheep farms and criteria of sustainability}

All the meat sheep farms that were sampled were located in the centre of France in an area where the main activity is meat sheep farming and experienced similar climatic conditions (average rainfall: $850-1000 \mathrm{~mm} /$ year, average mean temperature: $10.9-11.4^{\circ} \mathrm{C}$ ). The studied farmers made their living mostly from meat sheep production and had been involved in this production for several years as their main (or exclusive) source of income. Data from a set of 34 farms, 9 organic ( 2 in plain and 7 in semi- mountain areas) or 25 conventional farms in plain (11) or semi-mountain (14) areas were analysed for physical and financial performance of their flocks. These included the number of ewes, ewe and lamb mortalities, veterinary costs, and number of lambs produced and gross margin per ewe. The main characteristics are in Table 1 and their definitions were presented previously. ${ }^{11}$ The collection and analysis of data lasted one and a half day in each farm. We made the hypothesis that a sustainable meat sheep farm should have: low mortalities of ewes and lambs which permit to obtain good numerical productivity, low veterinary costs and complementary veterinary medicines, and hence good economic returns (ewe gross margin). The fertilizer use is an important part of farm input and it was used as an indicator of sustainability. The work input of the farmer, is increasing with sustainability but when too important it may be unsustainable. Finally, food autonomy is also a sign of sustainability, particularly in organic farms.

\section{Values and relationships between studied farm pa-} rameters

Some parameters in the meat sheep farms are highly variable like death of lambs or ewes, culling percentage, VET and CMV, WORKPR, fertilizer use and gross margin (Table 2). It means that they characterize the different farms. We proposed also an orientation for or against sustainability (Table 2). In the sustainability indices ${ }^{6,7}$ the parameters are considered as independent, although it is expected that several parameters are highly related, since farmers organize their actions with a general strategy including several parameters. ${ }^{12,13}$ Thus, death rate of lambs is logically and negatively impacting on numerical productivity and gross margin; it is also related to death rate in ewes (Table 3), which is indicative of a general health problem in some farms. The death of ewes is positively associated with high level of fertilizer use. The uses of complementary minerals, vitamins and complementary medicines (CMV) are positively associated with nitrogen fertilizer use on agricultural land and negatively with food autonomy. The veterinary costs are positively associated with CMV, culling and the different land fertilisations. Thus the health parameters are associated in a complex manner with several other sustainability parameters.

These relationships established by pairs of parameters may not imply a real relationship but may be based for example on a common association of two parameters with a third one. We thus undertook a more global analysis: a cluster analysis based on Gower coefficient (used since categorical-Plain or Organic and quantitative data can be included) and centroid aggregation was undertaken (MVSP statistical package) (Figure 1). ${ }^{14}$ Most of the variables are inter-related and analyses based on cluster analyses may be more appropriate since several variables are included in the construction of homogeneous clusters. The result of the cluster analysis is presented in dendrograms constructed on unweighted centroid clustering. The unweighted clustering gives equal weights to each object (variable) in each cluster. The centroid method replaces the clusters of object (variables) with their centroids, that is with points whose coordinates are averages of the objects in each group. The centroid method is more appropriate when one is interested in chaining among clusters (groups of variables) rather than primary connections among objects at lower levels, e.g., individual variables,$^{15}$ which was already performed using the Spearman correlations (see Table 3). Dendrograms are interpreted as follows: the cluster is highly validated when the Gower coefficient at the node is high (see GRMARG and AUTOFOOD with a Gower coefficient of over 0.90 ). The size of the flock was not associated with any other parameter and was not used in further analyses. Two main clusters are identified based on their high values of Gower coefficient. The first one concerns autonomy, work productivity, gross margin and production. The second includes fertilizer use, veterinary costs (VET and CMV), death of lambs and ewes, and type of farm, organic or not. The organic farms had higher prolificacy (169 vs 147), slightly lower culling ratio (19.6 vs 21.2), lower VET costs (3.8 vs 5.7), higher CMV costs (4.5 vs 3.2) and expectedly lower use of fertilizers (0 vs $23 \mathrm{~N} / \mathrm{ha}$ ) (data not shown). Organic farms experienced lower work productivity (51.6 vs 64.6) but surprisingly presented only a small increase of autonomy on all sheep food (83.4 vs 80.8). The small difference in autonomy of food is possibly due to the fact that most of the farms, conventional or organic relied much on pasture grazing. The comparison between organic and conventional is partly biased since more studied organic farms (7 out of 9) were located on semi-mountains. There were differences also between plain and semi-mountain farms, mostly in higher work productivity (numeric productivity in semi mountains (149 vs 125), lower culling (19 vs 24), lower deaths of lambs and ewes, and particularly lower costs for VET (3.9 vs 7.3) and CMV (2.3 vs 5.4), fertilizer use, and lower work productivity (54 vs 71) (data not shown). The differences appeared to be more important between plain and semi-mountain than between organic and conventional farms. This may explain that PLAIN and ORG (Figure 1) were in the same sub-cluster, since it was difficult to separate the effect of organic farming and localisation in plain or semi-mountain. Nevertheless, the environment was linked to health issues and we analysed the health issues in relation to farming system and location (Figure 2).

The axis 1 is the most representative with $96 \%$ of inertia (represented variability or variance) and the main variables are gross margin and numeric productivity. The importance of these parameters is not surprising since they include most of the economic productivity. The second axis has small inertia (2\%) and the main parameters are the fertilisation intensity, food autonomy and death of the lamb versus numeric productivity and gross margin. The ranking of farms on the two axes is similar $\left(r_{s}=0.68, p=0.00, n=34\right)$. Although the value of axis 2 was low, it was more easy to interpret graphically sustainability on this axis rather than on axis 1 . We checked the value of farm ranking on the basis of organic and conventional management and 
on the location of farm (plain or semi-mountain). The ranking on axis 1 allocated significantly $(\mathrm{p}<0.001)$ the organic farms in the $50 \%$ more sustainable farms and the plain farm in the $50 \%$ less sustainable farms. The ranking on the axis 2 indicated that semi-mountain farms were more sustainable than plain ones; the ranking of organic was not as clear cut as the one performed with Axis 1. Although organic farms were ranked among the most sustainable farms, many other conventional could pretend to sustainability in our sampling. This indicates that organic farming is not always the most sustainable in apparent contradiction with Nardone et al., ${ }^{3}$ who did not consider the economic issues at farm level, which we did. Also there is quite much variability among organic sheep systems. Toro-Mujica et al. ${ }^{16}$ distinguish between family subsistence system (low sustainability) and family commercial system (high sustainability). The low sustainability was due to mismanagement of resources, causing low productivity and finally lower gross margin. Health and reproductive success of sheep are good parameters (see the importance of numeric productivity in Figure 3) but they are not exclusive. Death rates in ewes and particularly lambs are indicators of sustainability but they are much less potent (see the low inertia of Axis 2), as expected, than a global sustainability set of parameters to classify the farms in terms of sustainability.

Table I Description of farm parameters

\begin{tabular}{|c|c|c|}
\hline Categories of parameters & Parameters (unit) & Abbreviations \\
\hline \multirow{3}{*}{ Animal Mortalities and Culling } & Mortalities of lambs (\% per year) & DEATHLA \\
\hline & Mortalities of ewes (\% per year) & DEATHEW \\
\hline & Culling of ewes ((\% per year) & CULL \\
\hline \multirow{5}{*}{ Animal Production } & Prolificacy & \\
\hline & & PROL \\
\hline & (number of offspring per lambing ewe and per year $\times 100$ ) & \\
\hline & Numerical productivity of the flock & \\
\hline & $\begin{array}{l}\text { (number of lambs produced (sold and females kept on farm for } \\
\text { reproduction } \times 100 \text { per ewe over } 12 \text { months during the year). }\end{array}$ & NUMPROD \\
\hline \multirow{4}{*}{ Health Costs } & Veterinary costs & VET \\
\hline & (euros per ewe and per year). & CMV \\
\hline & Complementary minerals and vitamins and other drugs & \\
\hline & (euros per ewe and per year) & \\
\hline Economic Return & $\begin{array}{l}\text { Gross margin per ewe and per year (euros per ewe and per year), as } \\
\text { the difference of value between gross product (e.g., sheep products sold, } \\
\text { subsidies for sheep) and input for the flock (e.g., feeding, reproduction, } \\
\text { veterinary costs, grassland fertilizers, services, fees). Fixed costs are not } \\
\text { included. }\end{array}$ & GRMARG \\
\hline \multirow{3}{*}{ Fertilizer Use } & Nitrogen N (per ha and per year) & N/ha \\
\hline & Phosphate $\mathrm{P}$ (per ha and per year) & $\mathrm{P} / \mathrm{ha}$ \\
\hline & Potassium K (per ha and per year) & K/ha \\
\hline \multirow[b]{2}{*}{ Work Input by Farmer } & $\begin{array}{l}\text { Productivity of the work is calculated using extended livestock units as } \\
\text { follows, [livestock units* }+(\mathrm{Ha} \text { for cereals and proteinaceous plants }) / 2 \text { ] }\end{array}$ & \\
\hline & $\begin{array}{l}\text { per full time worker on an annual basis. The livestock units are extended } \\
\text { since they incorporate livestock and cereals and proteinaceous plant } \\
\text { production. }\end{array}$ & WORKPR \\
\hline \multirow{3}{*}{ Food Autonomy } & $\%$ of herbage produced on farm & AUTHERB \\
\hline & $\%$ of fodder (herbage and corn silage) produced on farm & AUTFDD \\
\hline & $\%$ of all food produced on farm & AUTFOOD \\
\hline
\end{tabular}

*one ewe corresponds to 0.15 livestock unit 
Table 2 Parameters of sustainability in meat sheep farms- data from 2004 (see abbreviations in Table I)

\begin{tabular}{llllll}
\hline Parameters & Minimum & Maximum & Mean & Standard deviation & Suggested sustainability* \\
\hline NEWES & 99 & 1029 & 467 & 201 & nd \\
PROL & 117 & 205 & 153 & 23 & y \\
DEATHLA & 9.1 & 29 & 16.4 & 6 & $\mathrm{n}$ \\
NUMPROD & 92 & 202.7 & 140.1 & 30.9 & $\mathrm{y}$ \\
CULL & 10 & 40 & 20.7 & 7.7 & $\mathrm{y}$ \\
DEATHEW & 2 & 11.3 & 5.8 & 2.2 & $\mathrm{n}$ \\
CMV & 0 & 19.3 & 3.5 & 4.6 & $\mathrm{n}$ \\
VET & 1.1 & 12 & 5.1 & 2.6 & $\mathrm{n}$ \\
GRMARG & 44 & 132 & 86.4 & 25.8 & $\mathrm{y}$ \\
N/ha & 0 & 53.2 & 16.5 & 17.5 & $\mathrm{n}$ \\
P/ha & 0 & 44.9 & 12.2 & 14.4 & $\mathrm{n}$ \\
K/ha & 0 & 74.3 & 19.4 & 22.3 & $\mathrm{n}$ \\
WORKPR & 16 & 105.2 & 61 & 23 & $\mathrm{y}$ \\
AUTHERB & 59.1 & 93 & 74.3 & 8.2 & $\mathrm{y}$ \\
AUTFODD & 59.1 & 93.1 & 75 & 7.9 & $\mathrm{y}$ \\
AUTFOOD & 70 & 93.1 & 81.6 & 6.8 & \\
\hline
\end{tabular}

*nd, not determined; y, yes; increase sustainability, n, no, decreases sustainability

Table 3 Relationships (Spearman correlation coefficient) between animal health and reproduction related parameters and other sustainability parameters (see Table I for abbreviations)

\begin{tabular}{lllll}
\hline Parameters & DEATHLA & DEATHEW & CMV & VET \\
\hline NEWES & -0.253 & 0.039 & -0.292 & -0.072 \\
PROL & -0.173 & -0.213 & -0.158 & -0.197 \\
NUMPROD & $-\mathbf{0 . 4 5 8}$ & -0.327 & -0.01 & -0.132 \\
CULL & 0.102 & 0.044 & 0.172 & $\mathbf{0 . 5 5 8}$ \\
DEATHEW & $\mathbf{0 . 4 9 3}$ & 1 & -0.184 & 0.01 \\
CMV & 0.053 & -0.184 & 1 & $\mathbf{0 . 4 5 6}$ \\
VET & 0.146 & 0.01 & $\mathbf{0 . 4 5 6}$ & $\mathrm{I}$ \\
GRMARG & $\mathbf{- 0 . 4 9 0}$ & -0.318 & -0.231 & -0.129 \\
N/ha & 0.183 & 0.255 & $\mathbf{0 . 3 9 0}$ & $\mathbf{0 . 4 4 5}$ \\
P/ha & 0.149 & $\mathbf{0 . 3 3 2}$ & 0.038 & $\mathbf{0 . 4 1 4}$ \\
K/ha & 0.074 & $\mathbf{0 . 3 4 8}$ & -0.016 & $\mathbf{0 . 4 1 6}$ \\
WORKPR & -0.068 & 0.23 & -0.281 & 0.052 \\
AUTHERB & -0.31 & 0.01 & $\mathbf{- 0 . 4 6 8}$ & -0.315 \\
AUTFODD & -0.278 & 0.049 & $\mathbf{- 0 . 4 7 4}$ & -0.302 \\
AUTFOOD & 0.08 & 0.195 & $\mathbf{0 . 3 8 1}$ & $\mathbf{0 . 0 9 5}$ \\
\hline
\end{tabular}

In bold, Spearman correlation coefficients are significant at the 0.05 level (2-tailed) 


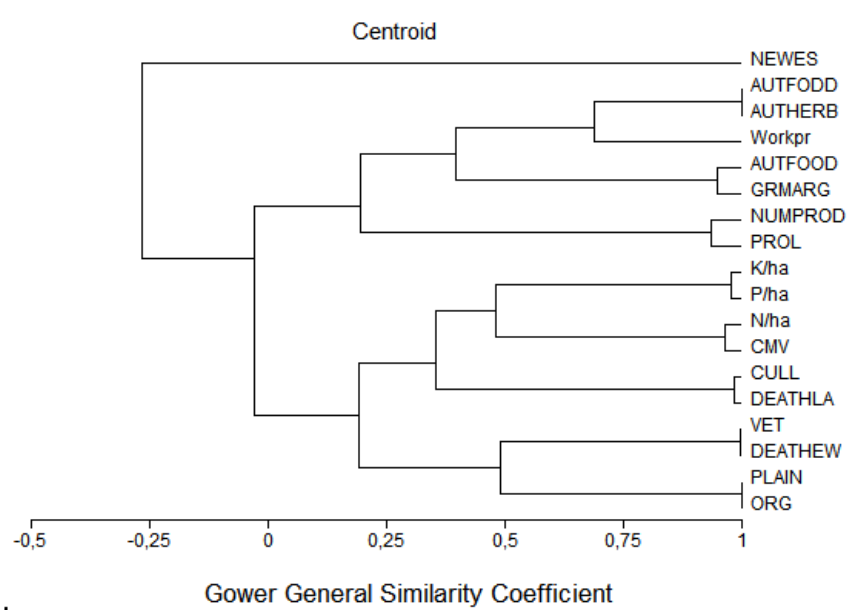

Figure I Cluster analysis of the main sustainability parameters in 34 farms (see Table I for abbreviations; ORG, organic).

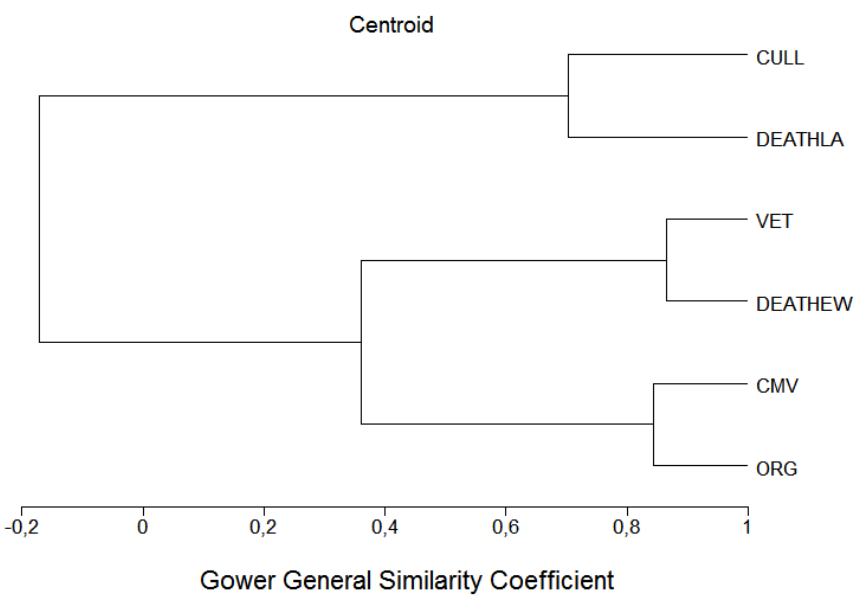

Figure 2 Cluster analysis of the main health parameters in relation to organic or conventional farming in 34 farms (see Table I for abbreviations; ORG, organic).

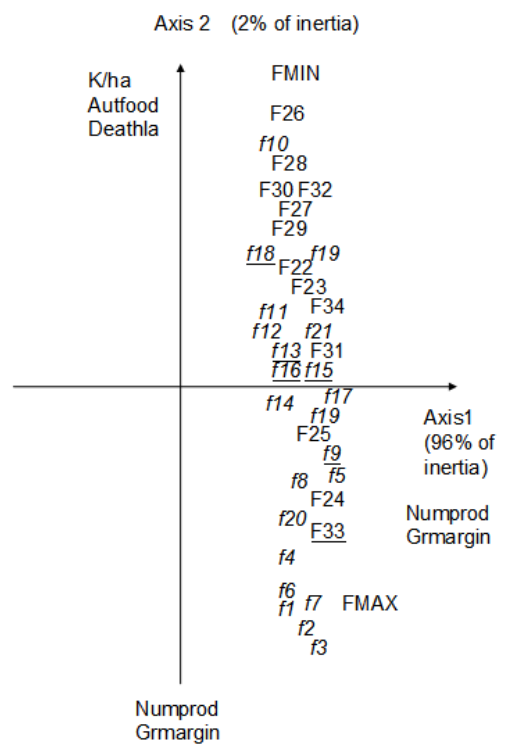

Figure 3 Axis I and Axis 2.

\section{Discussion and conclusion}

We constructed a global method for estimating sustainability in meat sheep farms that were considered as economically sustainable since they were ongoing for several years. The method was based on animal production and health, agricultural area fertilizer use, and economical parameters. We used sheep activity gross margin which may not be the best economical measure when sustainability is concerned and probably where capital investments are involved, measures of business return on capital, gearing and liquidity are also needed. ${ }^{17}$ It did not also consider as many parameters as global qualitative methods as MESMIS ${ }^{2}$ or RISE ${ }^{18}$ but was based on quantitative data and not only on farmers' declaration. The ResponseInducing Sustainability Evaluation (RISE) collect information on ecological, economic and social aspects through a questionnaire based interview with the farmer; it is then condensed into 12 sustainability indicators. The method presented in the paper was built on two steps: first, establishing which parameters could play a role on describing the farms (using cluster analysis) and second, to rank the farms on a sustainability scale using principal component analysis and farms as variables. The ranking was based on the position of actual farms in relation to virtual highly or poorly sustainable farms. The orientation of each farm parameter is flexible and may differ in different environments, and description of virtual highly or poorly susceptible farms is fully under decision of the different stakeholders in meat sheep production. Our ranking was apparently efficient since the organic farms were mostly allocated into the highly sustainable farms, and the plain farms (the most intensive in terms of production) into the low sustainable group of farms. However this set of parameters is difficult to obtain on a large number of farms due to the length of interview and control of data on farm for obtaining these parameters. A wider range of farms, including those known as probably finishing soon their activity on the basis of poor economic return or poor health management, would be valuable. Our sustainability ranking method has the interest of including animal production, health parameters, and economics. It is nevertheless limited to the evaluation on farm since it does not include any strictly environmental data. It was established on meat sheep but the methodology could be easily transposed to any other animal production.

\section{Acknowledgements}

We are grateful to the European Union for funding the Parasol Project and CIAB (Internal Committee for Organic Agriculture) from INRA for partial financing at the initiation of the project. The participation of the farmers interviewed is greatly appreciated.

\section{Conflict of interest}

Author declares that there is no conflict of interest.

\section{References}

1. Bauer S, Mickan S. Necessity for integration of agricultural, regional and environmental policy for disadvantaged rural areas. In: Laker J, Milne JA, editors. Livestock Systems in European Rural Development. LSIRD Network. Macaulay Land Use Research Institute, Aberdeen, Scotland, UK; 1997. p. 115-124.

2. Speelman EN, López-Ridaura S, Aliana Colomer N, et al. Ten years of Sustainability Evaluation using the MESMIS framework: Lessons learned from its application in 28 Latin American case studies. Int J of Sustainable Devpment \& World Ecol. 2007;14(4):345-361. 
3. Nardone A, Zervas G, Ronchi B. Sustainability of small ruminant organic systems of production. Livestock Prod Sci. 2004;90(1):27-39.

4. Fairbrother JR, Rosin CJ, Hunt LM, et al. Are conventional farmers conventional? Analysis of the environmental orientations of conventional New Zealand farmers. Rural Sociology. 2009;74(3):430-454

5. Gunnarsson S, Sonesson U, Stenberg M, et al. Scenarios for future Swedish dairy farming in relation to sustainability of animal health, environment and economy. In Aland A, Madec F, editors. Sustainable animal production - the challenges and potential developments for professional farming. 13th Congress of the International Society for Animal Hygiene. Tartu, Estonia, June 17-21, 2007, 2009. p. 445-458.

6. Vilain L. La méthode IDEA: indicateurs de durabilité des exploitations -guide d'utilisation. Dijon, France: Edition Éducagri, 2000. 100p.

7. Ghozlane F, Ziki B, Abbadie B, et al. Évaluation de la durabilité des exploitations ovines steppiques de la wilaya de Djelfa. Livestock Research for Rural Development. 2008;20(10):170.

8. Bartel R, Barclay E. Achieving sustainability in agriculture: lessons from Australia. Ecosystems and sustainable development VII Book Series: WIT Transactions on Ecology and the Environment. In: Brebbia CA, Tiezzi E, editors. Chianciano Terme, Italy: 7th International Conference on Ecosystems and Sustainable Development. 2009;122:640.

9. Greer AW, Corner-Thomas R, Logan CM, Kenyon PR, Morris ST, et al. Perceived importance of future research: results from a survey of sheep farmers. New Zealand J of Agric Res. 2015;58(4):359-370.

10. Benoit M, Laignel G. Constraints under organic farming on French sheep meat productions: a legal and economic point of view with an emphasis on farming systems and veterinary aspects. Vet Res. 2002;33(5):613-624.
11. Cabaret J, Benoit M, Laignel G, et al. Current management of farms and internal parasites by conventional and organic meat sheep French farmers and acceptance of targeted selective treatments. Vet Parasitol. 2009; 164(1): 21-29.

12. Nicourt C, Benoit M, Laignel G, et al. Approches sanitaires comparées d'éleveurs ovins allaitants biologiques et conventionnels. Innov Agronomiques. 2009;4:49-60.

13. Fairweather JR, Hunt LM. Can farmers map their farm system? Causal mapping and the sustainability of sheep/beef farms in New Zealand. $A g$ ric Hum Values. 2011;28(1):55-66

14. Multivariate Statistical Package (MVSP). User' manual. Version 3.1.KCS, Pentraeth, Wales, UK; 2001. p. 1-145.

15. Legendre P, Legendre L. Numerical ecology. Development in Environmental Modelling. Amsterdam: Elsevier; 1998;20:1-853.

16. Toro-Mujica P, Garcia A, Perea J, et al. A sustainability assessment of organic Dairy sheep systems in Castilla La Mancha (Spain). Revista Cientifica FCV-LUZ. 2014;24(6):553-562.

17. Scott JF, Scott JM, Cacho OJ . Whole-farm returns show true profitability of three different livestock management systems. Anim Prod Sci. 2013;53:780-787.

18. Grenz J, Thalmann C, Stämpfli A, et al. RISE- a method for assessing the sustainability of agricultural production at farm level. Rural Development News. 2009;1:5-9. 